\title{
Seleção de bioindicadores para monitoramento da mobilidade e persistência de herbicidas aplicados no solo ${ }^{1}$
}

\author{
Bioindicators selection for monitoring mobility and persistence of herbicides \\ applied in soil
}

\section{Kassio Ferreira Mendes ${ }^{2}$; Miriam Hiroko Inoue ${ }^{3}$; Ana Karollyna Alves de Matos ${ }^{4}$; Ana Cássia} Silva Possamai ${ }^{3}$; Monise Camila Tschope ${ }^{5}$; Barbara Ferreira Goulart ${ }^{5}$; Ronei Ben ${ }^{5}$

Resumo - O objetivo deste trabalho foi selecionar bioindicadores adequados para o monitoramento da mobilidade no solo e persistência dos herbicidas amicarbazone, ametryne, clomazone e diuron. Os experimentos foram conduzidos em casa de vegetação, utilizando vasos de polietileno de $250 \mathrm{~cm}^{3}$, com Latossolo Vermelho distroférrico. Em cada experimento, foi utilizado um herbicida (amicarbazone, ametryne, clomazone ou diuron) e três bioindicadores (10 sementes de cada espécie), distribuídos no delineamento em blocos ao acaso e esquema fatorial 5 $\mathrm{x} 3$, com três repetições. Os fatores estudados foram doses dos herbicidas $(0 ; 12,5 ; 25 ; 50$ e $100 \%$ da dose recomendada de cada herbicida) e espécies utilizadas como bioindicadores (Cucumis sativus, Brachiaria decumbens e Sorghum bicolor). Trinta dias após a semeadura foram cortadas as partes aéreas das plantas que foram mantidas em estufa de ventilação forçada a $40{ }^{\circ} \mathrm{C}$, visando à determinação da matéria seca. Dentre as espécies de bioindicadores testadas, evidenciou-se que C. sativus foi a que obteve maior sensibilidade às concentrações utilizadas de amicarbazone e ametryne no solo. A B. decumbens também obteve resposta adequada para biomonitoramento do clomazone e diuron, evidenciando essa ideia para futuros experimentos de mobilidade e persistência no solo de textura argilosa. O Sorghum bicolor foi a espécie que apresentou a menor inibição da biomassa, não sendo indicado como bioindicador dos herbicidas estudados.

Palavras-chaves: Contaminação, doses, controle, solo argiloso

\begin{abstract}
The objective of this work was to select appropriate bioindicators for monitoring the mobility in soil and persistence of amicarbazone, ametryne, diuron and clomazone herbicides. The experiments were conducted in greenhouse conditions, in polyethylene pots of $250 \mathrm{~cm}^{3}$ with dystroferric Red Latosol. In each experiment, it was used one herbicide (amicarbazone, ametryn, diuron or clomazone) and three bioindicators (10 seeds of each specie), distributed in randomized blocks design in a factorial scheme 5 x 3, with three replications. Studied factors were herbicides rates $(0 ; 12.5 ; 25 ; 50$ and $100 \%$ of recommended rate of each herbicide) and species used as bioindicators (Cucumis sativus, Brachiaria decumbens e Sorghum bicolor). Thirty days after sowing, aerial parts of plants were cut and kept in a forced air oven at $40{ }^{\circ} \mathrm{C}$ in order to determine dry matter. Among bioindicators species tested, C. sativus was the one that had the highest

\footnotetext{
${ }^{1}$ Recebido para publicação em 15/02/2012 e aceito em 13/08/2012.

${ }^{2}$ Mestrando em Agronomia (Produção Vegetal), Universidade Federal de Viçosa (UFV), Rodovia MG 230, Km 7 , CEP: 38810-000, Rio Paranaíba - MG. E-mail: <kassio_mendes_06@hotmail.com>;

${ }^{3}$ Docentes do Departamento de Agronomia da Universidade do Estado de Mato Grosso (UNEMAT), Tangará da Serra - MT;

${ }^{4}$ Mestranda em Agronomia (Agricultura), Universidade Estadual Paulista "Júlio de Mesquita Filho" (UNESP), Botucatu - SP;

${ }^{5}$ Discentes do curso de Agronomia da Universidade do Estado de Mato Grosso (UNEMAT), Tangará da Serra, MT.
} 
sensitivity to the concentrations of amicarbazone and ametryne applied in soil. B. decumbens also had an appropriate response for biomonitoring clomazone and diuron, evidencing this idea for further experiments of mobility and persistence in clay soil. S. bicolor specie had the lowest inhibition of biomass among the bioindicators for all herbicides evaluated, therefore not indicated to evaluate the behavior of these herbicides in soil.

Keywords: Contamination, rates, control, clay soil

\section{Introdução}

A utilização de herbicidas se destaca como ferramenta indispensável para a obtenção de alta produtividade em grandes áreas de cultivo, sendo uma prática bastante difundida em todo país (Inoue et al., 2011). Deste modo, tanto a eficiência no controle de plantas daninhas quanto o destino final no ambiente são controlados pela forma com que as moléculas se comportam no solo. Durante a aplicação dos herbicidas, parte destes é depositada sobre a planta alvo, entretanto, uma quantidade considerável acaba por atingir o solo direta ou indiretamente, podendo ser absorvidos pelas plantas, lixiviado e incorporado ao lençol freático, ou sofrer degradação (Vivian et al., 2007).

O mau uso e/ou redução das doses de herbicidas pré-emergentes têm alterado a eficiência no controle e afetado o efeito residual destes produtos. No solo, o efeito residual é proporcional à dose empregada, à persistência e à capacidade do herbicida em permanecer na camada de solo onde está o banco de sementes. Muitas vezes, a dose de um herbicida é eficiente para controle pontual, podendo apresentar atividade residual limitada (Evans et al., 2009).

O comportamento dos herbicidas nos solos tais como, o potencial de lixiviação e o efeito residual, pode ser avaliado mediante o uso de espécies vegetais, bioindicadoras, que demonstrem alta sensibilidade ao produto empregado (Blanco et al., 2010).

O amicarbazone apresenta como mecanismo de ação, a inibição da fotossíntese nas plantas daninhas, atuando na reação de Hill (fotossistema II). A morte das plantas, entretanto, pode ocorrer devido a outros processos, como a peroxidação de lipídeos e proteínas, promovendo a destruição das membranas e perda de clorofila (Rodrigues \& Almeida, 2011). É um herbicida sistêmico pertencente ao grupo químico das triazolinonas e possui enorme resistência à seca e longo período residual. Trabalhos desenvolvidos com Cucumis sativus (Carvalho et al., 2012) e Brachiaria decumbens (Negrisoli et al., 2007) como plantas bioindicadoras, evidenciaram sensibilidade ao amicarbazone, contribuindo para avaliação da atividade residual.

Ametryne é um herbicida pertencente ao grupo das s-triazinas utilizado no controle de plantas daninhas na cultura da cana-deaçúcar. É considerado um herbicida de caráter básico com pKa em torno de 4,0, que podem garantir uma persistência de até seis meses no solo (Inoue et al., 2003; Rodrigues \& Almeida, 2011). O mecanismo de ação deste produto causa a inibição da fotossíntese. Quando empregado em pós-emergência, os sintomas visuais evoluem geralmente para clorose generalizada e redução do desenvolvimento das plantas, ou podem ser mais acentuados com necrose nos pontos de contato da calda de pulverização com as folhas (Pires \& Oliveira, 2001; Procópio et al., 2003). O ametryne proporcionou excelente controle aos bioindicadores $C$. sativus (Inoue et al., 2011) e B. decumbens (Silva et al., 2002) na avaliação do efeito residual e na redução da interferência, respectivamente.

O clomazone pertence ao grupo químico das isoxazolidinonas, que atua na inibição da biossíntese de carotenoides e apresenta persistência no solo por cerca de 100 
a 120 dias. Quando aplicado em préemergência é absorvido pelas raízes, sendo translocado via xilema, pelo fluxo de transpiração (Rodrigues \& Almeida, 2011). Segundo Carvalho et al. (2012), o clomazone não controlou adequadamente o $C$. sativus na atividade residual de herbicidas recomendados para a cultura da cana-de-açúcar, quando aplicados ao solo na época seca. Já Monquero et al. (2008a), relataram que o Sorghum bicolor foi ideal para determinar a lixiviação da mistura ametryn + clomazone.

O diuron é um herbicida do grupo químico dos derivados da uréia, que promove a inibição da fotossíntese, causando sintomas aparentes, como a clorose foliar, seguido de necrose e a morte da planta (Pires \& Oliveira, 2001). Apresenta efeito residual de 40 a 70 dias variando de acordo com as características físico-químicas do solo, condições climáticas e a dose aplicada (Dias et al., 2003). Com a utilização de $B$. decumbens em bioensaios, foi possível determinar lixiviação do diuron em colunas de solo, além do efeito de métodos de redução da atividade microbiana na degradação deste herbicida (Inoue et al., 2008).

Diante do uso recorrente de herbicidas, aliada à escassez de informações referentes à sensibilidade de espécies bioindicadoras a esses compostos, objetivou-se neste trabalho selecionar dentre os bioindicadores Cucumis sativus L., Brachiaria decumbens Stapf e Sorghum bicolor L. Moench, o mais adequado para o monitoramento da mobilidade $\mathrm{e}$ persistência no solo argiloso dos herbicidas amicarbazone, ametryne, clomazone e diuron, aplicados em pré-emergência, por meio de bioensaios.

\section{Material e Métodos}

Quatro experimentos foram realizados em casa de vegetação utilizando amostras de Latossolo Vermelho - LV (Embrapa, 1999), provenientes do município de Tangará da Serra, MT (latitude 14³7'55'S, longitude $57^{\circ} 28^{\prime} 05^{\prime} \mathrm{W}$ e altitude de $488 \mathrm{~m}$ ), cujas características físico-químicas encontram-se representadas na Tabela 1.

Tabela 1. Características físico-químicas das amostras de solos utilizadas nos experimentos.

\begin{tabular}{|c|c|c|c|c|c|c|c|}
\hline \multirow{2}{*}{ Solo } & \multicolumn{2}{|c|}{ pH } & $\mathbf{A l}^{3+}$ & \multirow[t]{2}{*}{$\mathbf{H}^{+}+\mathrm{Al}^{3+}$} & \multirow{2}{*}{$\begin{array}{l}\mathrm{Ca}^{2+}+\mathrm{Mg}^{2+} \\
\left(\mathrm{cmol}_{\mathrm{c}} \mathbf{d m}^{-3}\right)\end{array}$} & \multirow[t]{2}{*}{$\mathbf{C a}^{2+}$} & \multirow[t]{2}{*}{$\mathbf{K}^{+}$} \\
\hline & $\left(\mathrm{CaCl}_{2}\right)$ & $\left(\mathbf{H}_{2} \mathbf{O}\right)$ & & & & & \\
\hline $\mathrm{LV}^{\underline{1}}$ & 5,80 & 6,70 & 0,00 & 3,13 & 6,00 & 4,31 & 0,37 \\
\hline $\begin{array}{c}P \\
\left(\mathrm{mg} \mathrm{dm}^{-3}\right)\end{array}$ & & & $\begin{array}{c}\text { CTC } \\
\left(\mathrm{cmol}_{\mathbf{c}} \mathbf{d m}^{-3}\right)\end{array}$ & $\begin{array}{l}\mathrm{V} \\
(\%)\end{array}$ & Areia & $\begin{array}{c}\text { Silte } \\
\left(\mathrm{g} \mathrm{kg}^{-1}\right)\end{array}$ & Argila \\
\hline 2,30 & & & 9,00 & 67,10 & 415,00 & 147,00 & 438,00 \\
\hline
\end{tabular}

As amostras de solo foram coletadas a uma profundidade de $5-10 \mathrm{~cm}$, peneiradas para remoção dos resíduos presentes na superfície do solo, e posteriormente secas ao ar e acondicionadas em vasos de polietileno com capacidade de $250 \mathrm{~cm}^{3}$.

Em cada experimento, foi utilizado um herbicida (amicarbazone, ametryne, clomazone ou diuron) e três bioindicadores, distribuídos no delineamento em blocos ao acaso e esquema fatorial $5 \times 3$, com três repetições. Os fatores estudados foram doses dos herbicidas $(0 ; 12,5$; 25; 50 e $100 \%$ da dose recomendada de cada herbicida) e espécies utilizadas como bioindicadores (C. sativus, B. decumbens e $S$. bicolor). As doses utilizadas foram as recomendadas para solos de textura argilosa (Rodrigues \& Almeida, 2011), além da testemunha sem aplicação de herbicidas. 
As aplicações dos herbicidas amicarbazone $\left(1,05 \mathrm{~kg} \mathrm{ha}^{-1}\right)$, ametryne $(2,40 \mathrm{~kg}$ $\left.\mathrm{ha}^{-1}\right)$, clomazone $\left(1,10 \mathrm{~kg} \mathrm{ha}^{-1}\right)$ e diuron $(3,20$ $\mathrm{kg} \mathrm{ha}^{-1}$ ), foram realizadas posicionando a barra do pulverizador a $0,5 \mathrm{~m}$ acima da borda superior dos vasos. Todas as aplicações foram realizadas com temperaturas inferiores a $35^{\circ} \mathrm{C}$ e umidade relativa superior a $60 \%$, com auxílio de um pulverizador costal pressurizado a $\mathrm{CO}_{2}$, munido de pontas tipo leque XR 110.02, com pressão de trabalho de $2 \mathrm{kgf} \mathrm{cm}^{-2}$, resultando em volume de calda de $200 \mathrm{~L} \mathrm{ha}^{-1}$.

Após a aplicação dos herbicidas, 10 sementes do bioindicador $(C$. sativus, $B$. decumbens e $S$. bicolor) foram semeadas na profundidade de $1 \mathrm{~cm}$, com $100 \%$ de germinação. Após a semeadura, os vasos foram mantidos com irrigação diária até 30 dias após a semeadura (DAS). Decorrido esse prazo, as partes aéreas das plantas bioindicadoras foram coletadas e colocadas em sacos de papel, levando-as à estufa de ventilação forçada a 40 ${ }^{\circ} \mathrm{C}$ até massa constante, visando à determinação da matéria seca.

Os dados foram transformados para porcentagem de inibição do acúmulo de matéria seca em relação à testemunha (dose de $0 \mathrm{~kg} \mathrm{ha}^{-1}$ ) e submetidos à análise de variância; posteriormente, foram ajustadas equações de regressão $(p>0,05)$. $\mathrm{Na}$ análise dos dados foi utilizado o programa de assistência estatística ASSISTAT (Silva \& Azevedo, 2002).

\section{Resultados e Discussão}

\section{Amicarbazone}

Os elevados níveis de inibição foram evidenciados para $C$. sativus com a aplicação de amicarbazone (Figura 1). Com aplicação de $50 \%$ da dose recomendada de amicarbazone, este bioindicador demonstrou excelente nível de controle $(100 \%)$. Os dados corroboram com Carvalho et al. (2012), que verificaram aos 70 dias após a aplicação de amicarbazone $(1,26 \mathrm{~kg}$ $\mathrm{ha}^{-1}$ ), controle de C. sativus superior a $90 \%$.
Para B. decumbens, o controle foi acima de $40 \%$, utilizando $40 \%$ da dose. Entretanto, na dose recomendada (100\%) o controle foi de $76 \%$, apresentando bom controle da plântula, em solo de textura argilosa com $43 \mathrm{~g} \mathrm{dm}^{3} \mathrm{de}$ MO (Figura 1). Ao avaliar a eficiência agronômica do amicarbazone $\left(1,4 \mathrm{~kg} \mathrm{ha}^{-1}\right) \mathrm{em}$ diferentes posicionamentos em relação à camada de palha de cana-de-açúcar e seu comportamento sob efeito da chuva simulada antes ou após aplicação do herbicida, sobre diversas plantas daninhas, em solo de textura média (19 $\mathrm{g} \mathrm{dm}^{3}$ de MO), Negrisoli et al. (2007) mencionaram que a espécie $I$. grandifolia mostrou-se mais sensível ao amicarbazone, demonstrando elevada sensibilidade (91-100\% de controle) desde 35 dias após a aplicação (DAA), dos tratamentos com o herbicida. Para B. decumbens, também obteve excelente nível de controle (91-100\%) desde 14 DAA, nos tratamentos em que o herbicida atingiu o solo, independentemente se aplicado diretamente sobre este ou lixiviado, em virtude da simulação de chuva após a aplicação do herbicida.

O bioindicador $S$. bicolor proporcionou a menor inibição $(54 \%)$ na dose recomendada de amicarbazone $\left(1,05 \mathrm{~kg} \mathrm{ha}^{-1}\right)$, reduzindo gradativamente em função da diminuição das doses, em Latossolo Vermelho (43 $\mathrm{g} \mathrm{dm}^{3} \mathrm{de}$ MO e 43,8\% de argila) (Figura 1). Corroborando com os dados, Bachega et al. (2009) observaram em casa de vegetação, que na precipitação de $35 \mathrm{~mm}$ de lâmina d'água, o amicarbazone $\left(1,05 \mathrm{~kg} \mathrm{ha}^{-1}\right)$ em Latossolo Vermelho-Amarelo (10-13 $\mathrm{g} \mathrm{dm}^{3}$ de $\mathrm{MO}$ e $27-$ $29 \%$ de argila), aplicado isolado ou em mistura com óleo mineral, não causou redução da matéria seca de S. bicolor, indicando que este poderia não ser um bioindicador adequado para esse herbicida. Ainda segundo o autor, outra possibilidade é que o produto lixiviou por todo o perfil do solo, devido à sua elevada solubilidade, e a concentração remanescente nas camadas superficiais não causou intoxicação às plantas. 


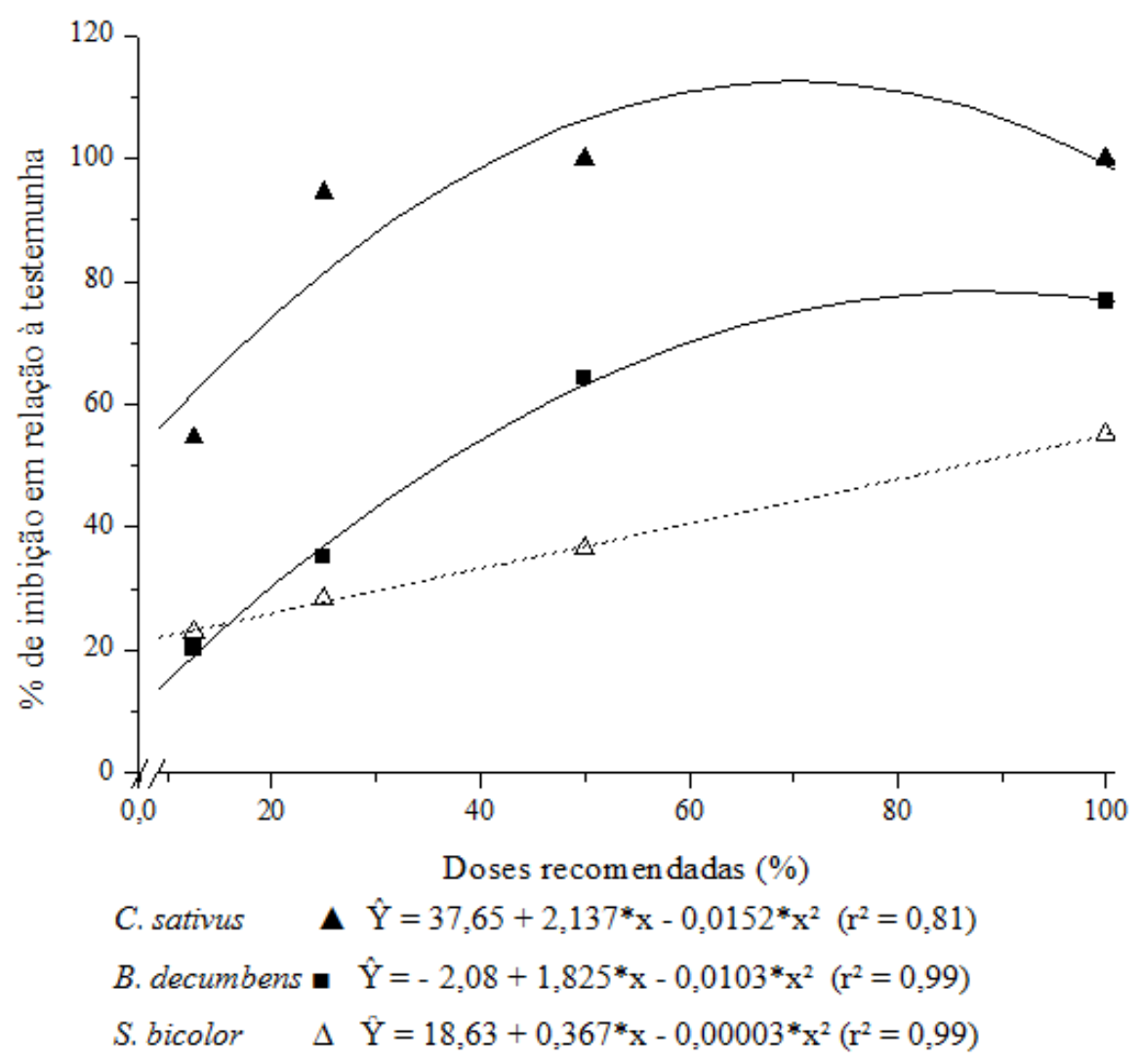

Figura 1. Porcentagem de inibição do acúmulo de matéria seca de bioindicadores, em relação à testemunha, com a aplicação de 12,5;25; 50 e $100 \%$ da dose recomendada de amicarbazone $\left(1,05 \mathrm{~kg} \mathrm{ha}^{-1}\right)$ em Latossolo Vermelho.

\section{Ametryne}

$\mathrm{Na}$ inibição da biomassa do C. sativus, notou-se elevado aumento no controle do bioindicador, evidenciando $40 \%$ de controle para a dose de $1,20 \mathrm{~kg} \mathrm{ha}^{-1}(50 \%)$, e controle de $100 \%$ do bioindicador para a dose recomendada $\left(2,40 \mathrm{~kg} \mathrm{ha}{ }^{-1}\right)$ de ametryne (Figura 2). Isso significa que, a utilização da dose recomendada é ideal para o controle efetivo deste bioindicador. Inoue et al. (2011) verificaram que a ametryne $\left(1,60\right.$ e $2,40 \mathrm{~kg} \mathrm{ha}^{-}$ ${ }^{1}$ ) em Latossolo Vermelho (43 $\mathrm{g} \mathrm{dm}^{3} \mathrm{de}$ MO e $43,8 \%$ de argila) proporcionou até os 40 DAA controle superior a $80 \%$ em plantas de $C$. sativus, diminuindo gradativamente após esse período.

O bioindicador $S$. bicolor não apresentou inibição satisfatória da biomassa, nas diferentes doses de ametryne, atingindo controle máximo de $28 \%$ na dose recomendada $(100 \%)$. Entretanto, com $12,5 \%$ da dose recomendada não se observou controle do bioindicador (Figura 2). Já Monquero et al. (2008b) alcançaram controle eficiente de $100 \%$ do S. bicolor até os 40 DAA com a aplicação da mistura ametryne + clomazone $(1,5+1,0 \mathrm{~kg}$ $\mathrm{ha}^{-1}$ ) em Latossolo Vermelho distroférrico (36 $\mathrm{g} \mathrm{dm}^{-3}$ de $\mathrm{MO}$ e $15 \%$ de argila) e em Latossolo Vermelho distrófico $\left(22 \mathrm{~g} \mathrm{dm}^{-3}\right.$ de $\mathrm{MO}$ e $51 \%$ de argila) sem palha.

B. decumbens apresentou $56 \%$ de controle para a dose recomendada de ametryne (2,40 $\mathrm{kg} \mathrm{ha}^{-1}$ ) em Latossolo Vermelho (43 g $\mathrm{dm}^{3}$ de MO e 43,8\% de argila), não sendo muito eficiente para avaliar 0 biomonitoramento desse herbicida no solo 
(Figura 2). Em contra partida Silva et al. franco-argiloarenosa $(2,11 \%$ de $\mathrm{MO}$ e $34 \%$ de (2002) observaram que ametryne aplicado em pós-emergência $\left(2,50\right.$ e $\left.3,75 \mathrm{~kg} \mathrm{ha}^{-1}\right)$ em argila), proporcionou controle acima de $90 \%$ Podzólico Vermelho-Amarelo câmbico, textura em B. decumbens.

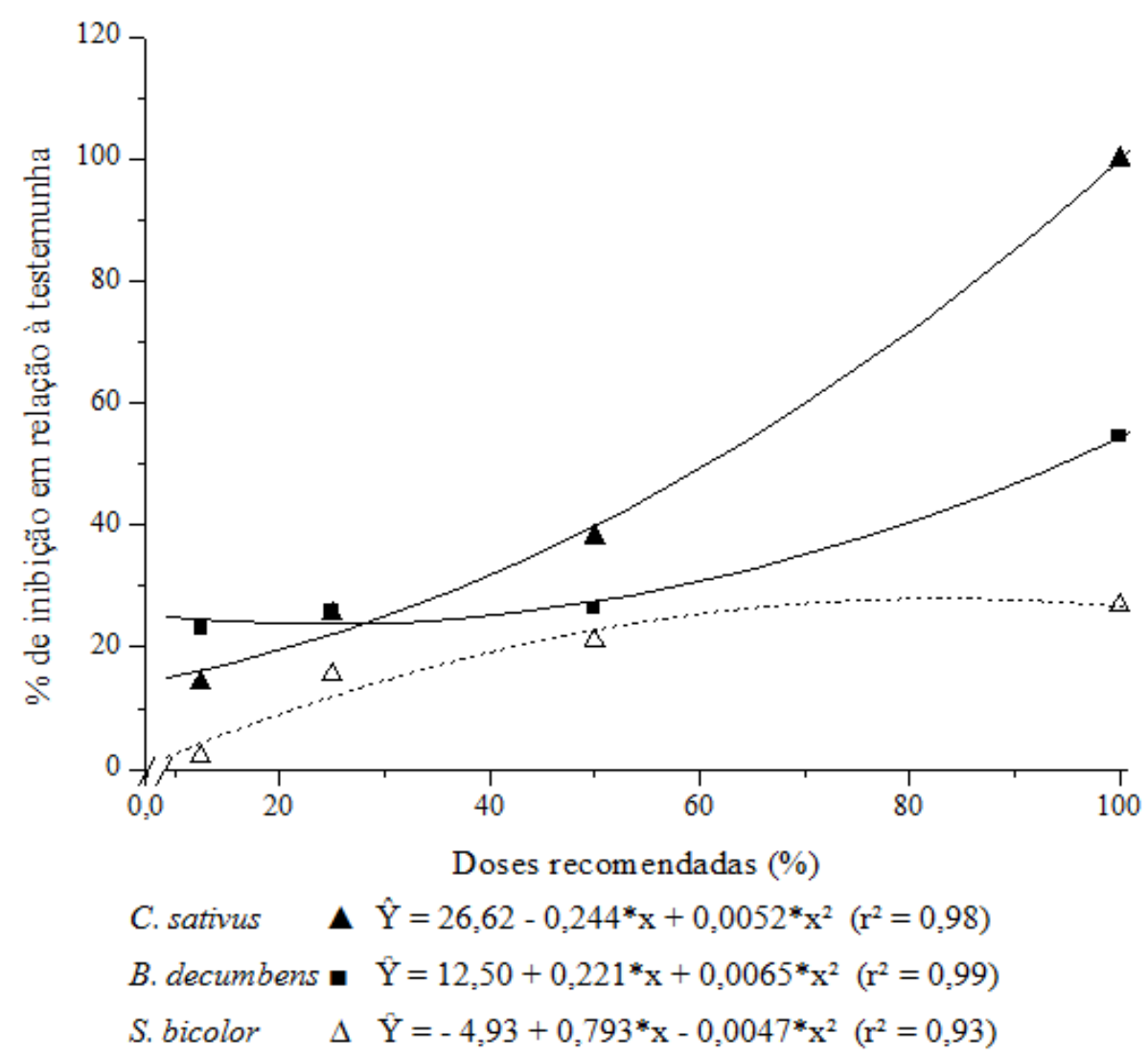

Figura 2. Porcentagem de inibição do acúmulo de matéria seca de bioindicadores, em relação à testemunha, com a aplicação de 12,$5 ; 25 ; 50$ e $100 \%$ da dose recomendada de ametryne $(2,4 \mathrm{~kg}$ $\mathrm{ha}^{-1}$ ) em Latossolo Vermelho.

\section{Clomazone}

Verificou-se que doses acima de $50 \%$ da dose recomendada de clomazone o controle foi de $100 \%$ para $B$. decumbens, evidenciando a possibilidade da realização de futuras pesquisas sobre mobilidade e persistência de clomazone com essa espécie vegetal (Figura 3). Dados similares também foram observados por Inoue et al. (2011), em que o clomazone aplicado no Latossolo Vermelho distroférrico de textura argilosa (43 $\mathrm{g} \mathrm{dm}^{-3}$ de $\mathrm{MO}$ e $43,8 \%$ de argila) proporcionou controle da $B$. decumbens acima de $80 \%$ até os 39 DAA, em ambas as doses $\left(0,90\right.$ e $\left.1,10 \mathrm{~kg} \mathrm{ha}^{-1}\right)$.

Em doses mínimas (12,5\%) de clomazone, foi possível observar inibição de $36 \%$ da biomassa do C. sativus. Portanto, na dose recomendada de clomazone observou-se $60 \%$ de controle (Figura 3). O bioindicador $S$. bicolor tem alcançado apenas $12 \%$ de controle para $50 \%$ da dose recomendada de clomazone $\left(1,10 \mathrm{~kg} \mathrm{ha}^{-1}\right)$ (Figura 3).

Trabalhos realizados por Santos et al. (2003) indicaram que o clomazone aplicado na cultura da soja afetou culturas sucessivas de 
trigo, aveia e cevada devido à sua persistência de 150 DAA para implantação da cultura no solo, o que demanda um intervalo mínimo subsequente.

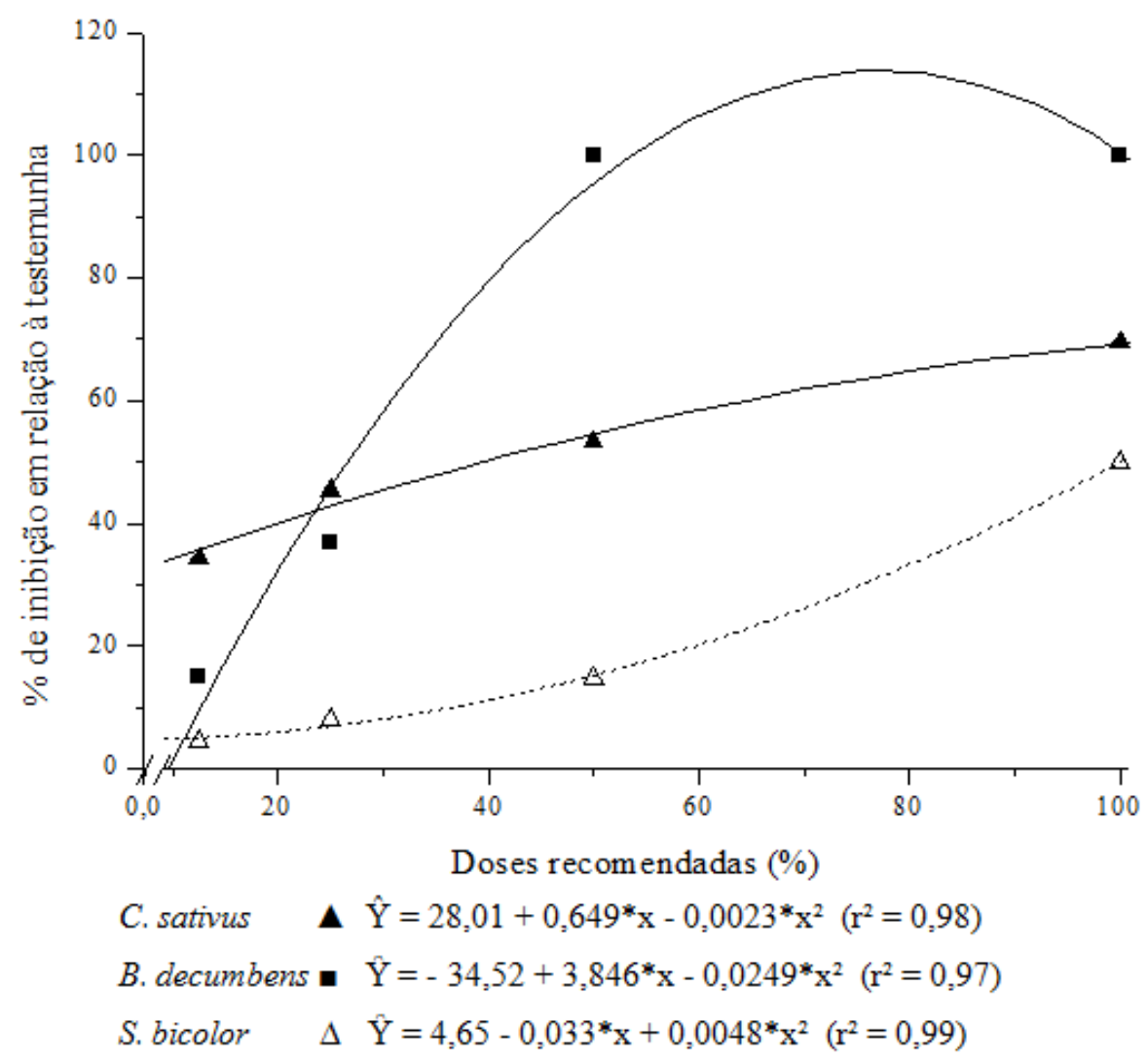

Figura 3. Porcentagem de inibição do acúmulo de matéria seca de bioindicadores, em relação à testemunha, com a aplicação de 12,5; 25; 50 e $100 \%$ da dose recomendada de clomazone $(1,1 \mathrm{~kg}$ $\mathrm{ha}^{-1}$ ) em Latossolo Vermelho.

\section{Diuron}

A espécie vegetal B. decumbens apresentou inibição superior ao $C$. sativus somente com a utilização de $100 \%$ da dose de diuron, controlando cerca de $90 \%$ das plantas (Figura 4). Inoue et al. (2011) observaram que a aplicação de diuron $\left(3,20 \mathrm{~kg} \mathrm{ha}^{-1}\right)$ em solos argilosos proporcionou excelente controle de $B$. decumbens com o uso da dose recomendada, e acima de $90 \%$, na menor dose $\left(1,60 \mathrm{~kg} \mathrm{ha}^{-1}\right)$ até 22 DAA.

Com a aplicação de diuron, para o bioindicador $C$. sativus obteve-se o máximo de controle (65\%), com aplicação de $100 \%$ da dose recomendada, e na dose de $25 \%$ de diuron o controle foi de apenas $23 \%$ dessa planta bioindicadora (Figura 4).

Foi observado por Dias et al. (2003), trabalhando com aplicação de diuron, redução significativa da massa seca de duas espécies de Digitaria com o aumento da dose de diuron aplicada, ocorrendo diferença de sensibilidade entre as espécies. Segundo os autores, para $D$. nuda necessitou de doses maiores para apresentar a mesma redução no crescimento. A dose de campo proporcionou redução da massa seca em torno de 70 e $90 \%$ para $D$. nuda e $D$. ciliaris, respectivamente.

S. bicolor apresentou controle insatisfatório com a aplicação de 50 e $100 \%$ da 
dose recomendada, não promovendo controle acima de $25 \%$ das plantas (Figura 4).

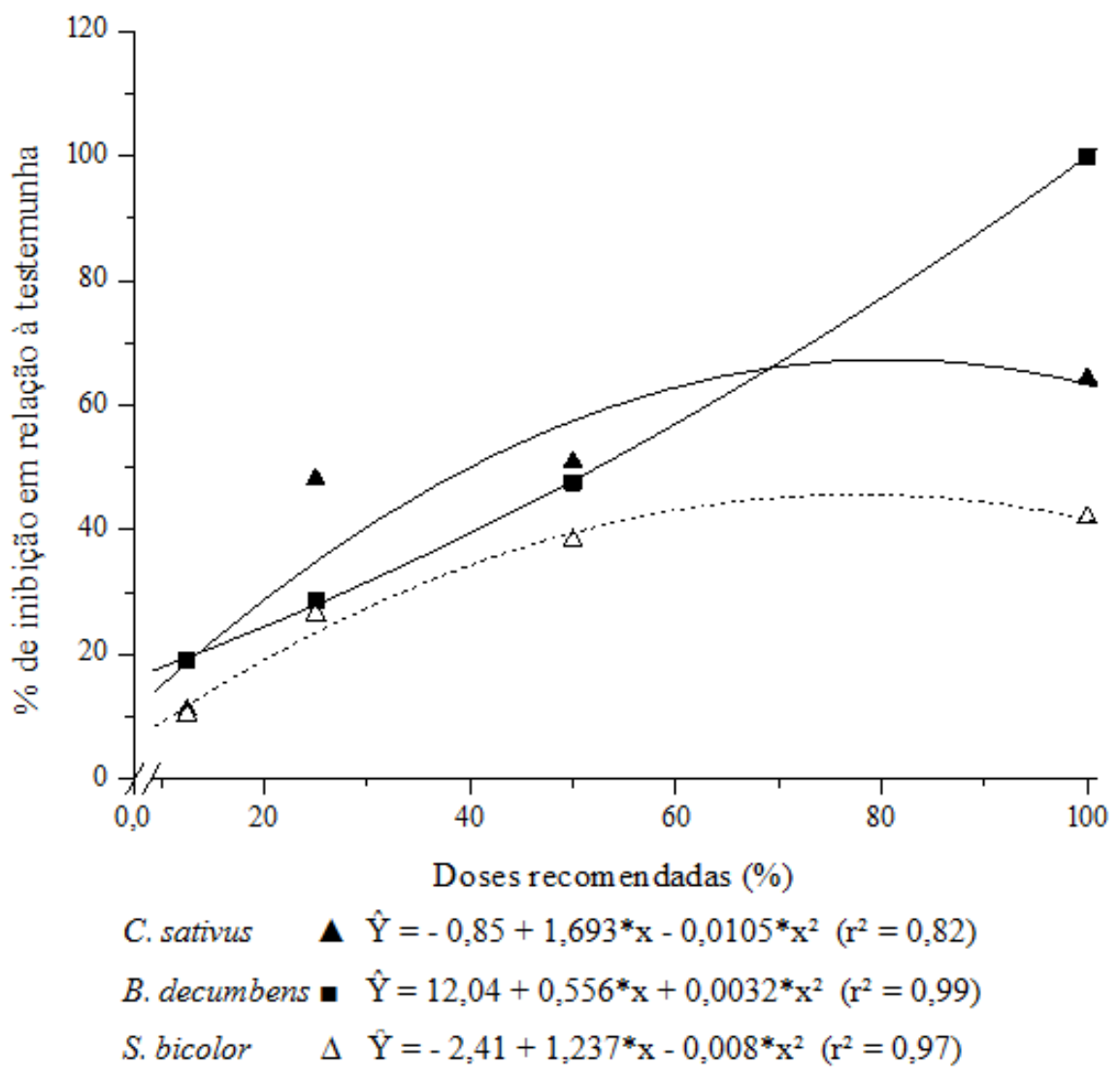

Figura 4. Porcentagem de inibição do acúmulo de matéria seca de bioindicadores, em relação à testemunha, com a aplicação de 12,$5 ; 25 ; 50$ e $100 \%$ da dose recomendada de diuron $\left(3,2 \mathrm{~kg} \mathrm{ha}^{-1}\right)$ em Latossolo Vermelho.

No geral, os bioindicadores $C$. sativus e B. decumbens apresentaram as maiores sensibilidades aos herbicidas amicarbazone, ametryne, clomazone e diuron, independentemente das doses empregadas.

\section{Conclusões}

Dentre as espécies de bioindicadores testadas, evidenciou-se que a espécie $C$. sativus foi a que obteve maior sensibilidade às concentrações utilizadas de amicarbazone e ametryne no solo.

A espécie $B$. decumbens também obteve resposta adequada para biomonitoramento dos herbicidas clomazone e diuron, evidenciando ideal para futuros experimentos de mobilidade e persistência no solo de textura argilosa.

O S. bicolor foi a espécie que apresentou a menor inibição da biomassa, não sendo indicado como bioindicador dos herbicidas estudados.

\section{Referências}

BACHEGA, T.F. et al. Lixiviação de sulfentrazone e amicarbazone em colunas de solo com adição de óleo mineral. Planta Daninha, v.7, n.2, p.363-370, 2009.

BLANCO, F.M.G.; VELINI, E.D; BATISTA FILHO, A. Persistência do herbicida 
sulfentrazone em solo cultivado com cana-deaçúcar. Bragantia, v.69, n.1, p.71-75, 2010.

CARVALHO, S.J.P. et al. Atividade residual de seis herbicidas aplicados ao solo em época seca. Revista Ceres, v.59, n.2, p.278-285, 2012.

DIAS, N.M.P. et al. Absorção e translocação do herbicida diuron por espécies suscetível e tolerante de capim-colchão (Digitaria spp.). Planta Daninha, v.21, n.2, p.293-300, 2003. EMBRAPA, Empresa Brasileira de Pesquisa Agropecuária. Centro Nacional de Pesquisa de Solos. Sistema Brasileiro de Classificação de Solos. Rio de Janeiro: Embrapa Solos, 1999.

EVANS, G.J.; BELLINDER, R.R.; GOFFINET, M.C. Herbicidal effects of vinegar and a clove oil product on redroot pigweed (Amaranthus retroflexus) and velvetleaf (Abutilon theophrasti). Weed Technology, v.23, n.2, p.292-299, 2009.

INOUE, M.H. et al. Critérios para avaliação do potencial de lixiviação dos herbicidas comercializados no estado do Paraná. Planta Daninha, v.21, n.2, p.313-323, 2003.

INOUE, M.H. et al. Efeito residual de herbicidas aplicados em pré-emergência em diferentes solos. Planta Daninha, v.29, n.2, p.429-435, 2011.

INOUE, M.H. et al. Lixiviação e degradação de diuron em dois solos de textura contrastante. Acta Scientiarum Agronomy, v.30, n.supl., p.631-638, 2008.

MONQUERO, P.A. et al. Lixiviação de clomazone + ametryn, diuron + hexazinone e isoxaflutole em dois tipos de solo. Planta Daninha, v.26, n.3, p.685-691, 2008a.

MONQUERO, P.A. et al. Mobilidade e persistência de herbicidas aplicados em préemergência em diferentes solos. Planta Daninha, v.26, n.1, p.411-417, 2008 b.

NEGRISOLI, E. et al. Controle de plantas daninhas pelo amicarbazone aplicado na presença de palha de cana-de-açúcar. Planta Daninha, v.25, n.3, p.603-611, 2007.
PIRES, N.M; OLIVEIRA, W.R. Alelopatia. In: OLIVEIRA JR, R.S.; CONSTANTIN, J. (Coord.) Plantas Daninhas e seu Manejo. Guaíba: Livraria e Editora Agropecuária, 2001. p.145-185.

PROCÓPIO, S.O. et al. Manejo de plantas daninhas na cultura da cana-de-açúcar. Viçosa: UFV, 2003. 150p.

RODRIGUES, B.N. \& ALMEIDA, F.S. Guia de herbicidas. 6. ed. Brasília: Independente, 2011, 697p.

SANTOS, R.L.B.; SPEHAR, C.R.; VIVALDI, L. Quinoa (Chenopodium quinoa) reaction to herbicide residue in a Brazilian Savannah soil. Pesquisa Agropecuária Brasileira, v.38, n.6, p.771-776, 2003.

SILVA, F.A.S. \& AZEVEDO, C.A.V. Versão do programa computacional Assistat para o sistema operacional Windows. Revista Brasileira Produtos Agroindustriais, v.4, n.1, p.71-78, 2002.

SILVA, W. et al. Redução da interferência de Brachiaria decumbens na formação de pastagem com Penisetum purpureum através de herbicidas. Planta Daninha, v.20, n.2, p.273-281, 2002.

VIVIAN, R. et al. Persistência e lixiviação de ametryne e trifloxysulfuron-sodium em solo cultivado com cana-de-açúcar. Planta Daninha, v.25, n.1, p.111-124, 2007. 